Revista "Política y Estrategia" N 127, 2016, pp. 209-211

ISSN 0716-7415

Academia Nacional de Estudios Políticos y Estratégicos

Institucionalidad de la defensa en Suramérica

Cristian Faundes Sánchez

\title{
INSTITUCIONALIDAD DE LA DEFENSA EN SURAMÉRICA*
}

\section{CRISTIÁN FAUNDES SÁNCHEZ•}

El libro constituye uno de los esfuerzos más significativos para sistematizar la información relativa a la institucionalidad de la Defensa regional. Con bastante detalle da cuenta de la estructura que tiene el sector en los 12 países miembros del Consejo de Defensa Suramericano de UNASUR e incorpora una "descripción y análisis de los aspectos normativos, orgánicos y funcionales de los sistemas nacionales de defensa" ( $p$. 9).

Recoge lo obrado entre 2011 y 2014 en una de las áreas de trabajo permanente del CEED, dedicada a la Institucionalidad de la Defensa. La principal virtud es que se presenta como un compendio organizado de política, organización, estructura, y funcionamiento del sector. Dada la complejidad de la materia, el estudio convoca a

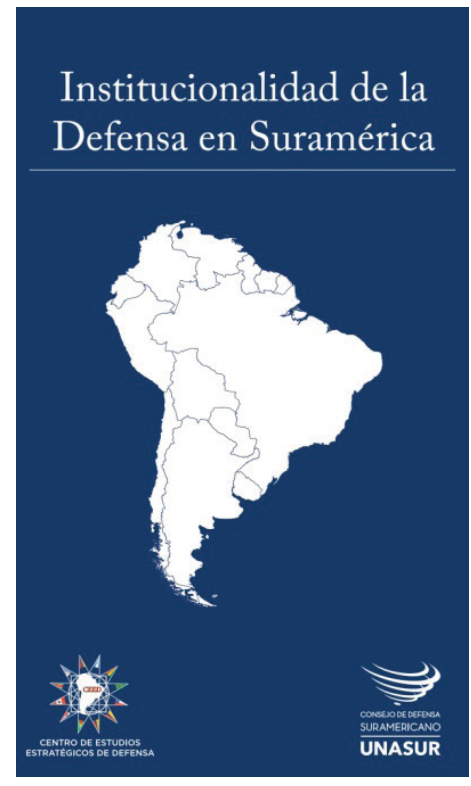
un equipo compuesto por veinte personas que incluyen los delegados del Centro de Estudios Estratégicos de Defensa, de la administración actual y la anterior, junto a otros colaboradores.

En la elaboración del texto destaca el trabajo de trasfondo que permite estructurar los datos en un cuerpo coherente de información. Se trata de la elaboración de una metodología consensuada, que aplicada a nivel regional, "permitió la homologación de descriptores y categorías de análisis de la información oficial de los países, con el objetivo de sistematizar y transparentar la información de los ordenamientos políticoinstitucionales del sector defensa en los países miembros del CDS-UNASUR" (p. 9). $Y$ este es probablemente el elemento central que justifica la labor desempeñada.

Centro de Estudios Estratégicos de Defensa (CEED), Consejo de Defensa Suramericano (CDS), UNASUR, Buenos Aires: CEED-CDS UNASUR. 2015. 523 páginas (sin ISBN).

- Magíster en Seguridad y Defensa, mención Política de Defensa (ANEPE). Magíster en Ciencias Militares, mención Conflicto y Negociación Internacional (ACAGUE). Investigador, Centro de Estudios Estratégicos, Academia de Guerra del Ejército de Chile. cgfaundes@gmail.com 
El libro, además de constituirse en una fuente clave que exhibe los aspectos determinantes de la política y legislación del sector Defensa en cada país de la región, provee información que permite desarrollar una mirada comparada. Pero todavía más, el proceso de elaboración y publicación del texto da cuenta de dos hechos muy significativos. El primero es que su contenido trasciende el ámbito académico debido al acuerdo metodológico que alcanzaron los diferentes representantes de ministerios de Defensa que desempeñan funciones en el CEED, en términos de definir los criterios para apreciar el sector. En segunda instancia, este hecho permite vislumbrar el germen en torno a la homologación de criterios, no solo para observar la institucionalidad en el ámbito de la Defensa, sino que también al momento de desarrollarla, construirla. No se puede soslayar el alcance político de la iniciativa que tiene como resultado esta publicación.

En cuanto al contenido propiamente tal, destaca el extenso y detallado trabajo en que se caracteriza al sector Defensa en cada uno de los países de la región. Pero llama todavía más la atención el capítulo dedicado a las "Principales características de la Defensa en Suramérica", y las ocho recomendaciones que el CEED expone en la "Introducción", según se detalla a continuación.

Entre las principales características se aprecia la tendencia a desarrollar el principio de conducción y operación conjunta de las FF.AA. Se observa también que en algunos países el instrumento militar de la Defensa presenta otros componentes adicionales a los tradicionales, con funciones diversas, "que incluyen responsabilidades en materia de Seguridad interna" (p. 17). Conforme a ello se identifica una disparidad en cuanto a la delimitación del sector Defensa Nacional y Seguridad Interna. Relacionado a lo anterior, la arquitectura que definen los países para sostener el sector no es homogénea. En cuanto a la Política de Defensa, destaca como principal coincidencia regional la concepción y disposición estratégica de naturaleza defensiva y cooperativa (p. 22), tengamos en cuenta que esta observación la formula un organismo que promueve la seguridad cooperativa. Respecto de las misiones de las FF.AA., el texto da cuenta que algunos países han incrementado sus actividades en seguridad pública o interior (p. 26).

Las recomendaciones están orientadas a fortalecer los objetivos y misión que inspiran al CDS, al CEED y la Escuela Suramericana de Defensa, y en forma esencial destaca la mirada hacia una gobernabilidad democrática de la Defensa. En este sentido, de las ocho propuestas quisiera remarcar el valor que tiene el desarrollo de estudios comparativos entre los países miembros de UNASUR sobre la viabilidad de desarrollar la carrera de civiles en el sector de la Defensa, que los autores del libro vinculan con la participación ciudadana en la defensa nacional. Respecto de la 
Ciberdefensa, los autores propician un enfoque común y consensuado, muy válido aunque discutible, debido a que una visión única en esta materia específica finalmente nos podría hacer más vulnerables; el intercambio en términos académicos y prácticos podría ser más enriquecedor.

Finalmente, se trata de un texto esencial que podría considerarse como un compendio o manual para académicos o asesores que se interesen en realizar estudios comparados, quienes busquen la normativa específica que regula el sector defensa en los países de UNASUR, o legisladores o políticos que quisieran indagar cómo otros países han diseñado la estructura de defensa para enfrentar la incertidumbre. 